\title{
Modeling and Limits of Advanced HT-Magnets
}

\author{
Thomas Schrefl, Josef Fidler, and Werner Scholz
}

\begin{abstract}
This paper combines microstructural investigations using transmission electron microscopy with micromagnetic finite element simulation of the magnetic domain wall pinning behavior of novel $\mathrm{Sm}(\mathrm{Co}, \mathrm{Fe}, \mathrm{Cu}, \mathrm{Zr})_{7,4-8,0}$ permanent magnet materials applicable up to $550^{\circ} \mathrm{C}$. A finite element method was used to simulate domain wall pinning in $\mathrm{SmCo}_{5} / \mathrm{Sm}_{2} \mathrm{Co}_{17}$ based permanent magnets. The finite element model was built-according to the cellular microstructure obtained from TEM investigations. The numerical results show a strong influence of the dimension of the cell boundary phase on the coercive field, which significantly increases with the extension of the $1: 5 / 7$-type cell boundary phase. The calculated values of the coercive field are in the range from 1000-2000 $\mathrm{kA} / \mathrm{m}$ assuming a cell size varying from 80-160 $\mathrm{nm}$. The difference of the magnetocrystalline anisotropy between cell boundary and cell interior phases is determined by the $\mathrm{Cu}$-content of the magnet. Due to the lower Curie temperature of the $\mathrm{Cu}$-containing cell boundary phase high coercive fields are obtained at elevated temperatures $\left(>400^{\circ} \mathrm{C}\right)$
\end{abstract}

Index Terms-HT-magnets, micromagnetics, microstructure, permanent magnets.

\section{INTRODUCTION}

$\mathbf{T}$ HE SEARCH for novel soft and hard magnetic materials for high temperature (HT) advanced power applications is worldwide an active area of research. The increase of the operating temperature of motors, generators and other electronic devices leads to an improvement of the efficiency. In the development of high temperature magnets the activities concentrate on the improvement of existing hard magnetic materials, such as the precipitation hardened $\mathrm{Sm}(\mathrm{Co}, \mathrm{Fe}, \mathrm{Cu}, \mathrm{Zr})_{z}$ magnets, and on the search for new compounds with sufficient high values of magnetization and coercive field at elevated temperatures. Precipitation hardened $\mathrm{SmCo}_{5} / \mathrm{Sm}_{2} \mathrm{Co}_{17}$ based permanent magnets have been developed during the past 20 years [1]. It was shown that the influence of the cellular precipitation structure on the coercive field lead to a domain wall pinning controlled mechanism [2], [3].

With increasing effort to improve the thermal stability of $\mathrm{SmCo}_{5} / \mathrm{Sm}_{2} \mathrm{Co}_{17}$ based permanent magnets numerical models have been developed, in order to obtain a better understanding of the pinning mechanism. Katter [4] proposed a two-dimensional model based on the local wall energy to derive the coercivity of $\mathrm{Sm}(\mathrm{Co}, \mathrm{Fe}, \mathrm{Cu}, \mathrm{Zr})_{7.5}$ magnets. Chui [5] applied a Monte Carlo method to simulate the pinning of domain walls at finite temperatures. Optimal microstructures and the upper limits of the coercive field of the $\mathrm{Cu}$-containing,

Manuscript received February 14, 2000. This work was supported by the EC Project HITEMAG (GRD1-1999-11125) and the Austrian Science Fund (Y132PHY).

The authors are with the Institute of Applied and Technical Physics, Vienna University of Technology, A-1040 Wien, Austria (e-mail: fidler@tuwien.ac.at). Publisher Item Identifier S 0018-9464(00)07982-6. precipitation hardened $\mathrm{SmCo} 2: 17$ magnets optimized for HT-applications are predicted from the our micromagnetic model calculations. The three-dimensional finite element model takes into account the rhombohedral cellular structure of the magnet. According to the transmission electron microscope investigations our micromagnetic simulations assumed a cellular precipitation structure in the range of $50-250 \mathrm{~nm}$. The equilibrium position of the domain walls are calculated from the minimization of the total magnetic Gibb's free energy. Section II of the paper describes the TEM investigation of the microsctructure. Section III presents the micromagnetic finite element simulations that give a straight forward explanation of the pinning mechanism in $\mathrm{Sm}(\mathrm{Co}, \mathrm{Fe}, \mathrm{Cu}, \mathrm{Zr})_{7.5}$ magnets. The influence of $\mathrm{Co}$ - and $\mathrm{Cu}$-content and the overall composition ( $z$-value) on the magnetic properties will be shown and possible mechanisms for the change of the microstructure during the HT operation of the magnet will be discussed

\section{MicrostruCtural CHARACTERIZATION}

A new series of $\mathrm{Sm}\left(\mathrm{Co}_{w} \mathrm{Fe}_{v} \mathrm{Cu}_{x} \mathrm{Zr}_{y}\right)_{z}$ magnets has been developed with ${ }_{i} H_{c}$ up to $1050 \mathrm{kA} / \mathrm{m}$ at $400^{\circ} \mathrm{C}$. These magnets show low temperature coefficients of ${ }_{i} H_{c}$ and a straight line $\mathrm{B}$ versus $\mathrm{H}$ (extrinsic) demagnetization curve up to $550^{\circ} \mathrm{C}$. High $\mathrm{Cu}$-, low $\mathrm{Fe}$ - and low $z$-values were found to contribute to high coercivity at high temperatures [6], [7]. The TEM micrograph of Fig. 1(a) of a sintered magnet with ${ }_{i} H_{c}=$ $580 \mathrm{kA} / \mathrm{m}$ at $500^{\circ} \mathrm{C}$ shows a cellular precipitation structure with about $60 \times 120 \mathrm{~nm}$ in size at the magnetic optimum state. The rhombic cells of the type $\mathrm{Sm}_{2}(\mathrm{Co}, \mathrm{Fe})_{17}(\mathrm{~A})$ are separated by a $\mathrm{Sm}(\mathrm{Co}, \mathrm{Cu}, \mathrm{Zr})_{5-7}$-cell boundary phase (B) [8]-[10]. The development of the continuous, cellular precipitation structure is controlled by the growth process and the chemical redistribution process [11] and is determined by the direction of zero deformation strains due to the lattice misfit between the different phases. The cellular precipitation structure is formed during the isothermal aging procedure, whereas the chemical redistribution of the transition metals during the step aging procedure increases the coercivity of the final magnet. It should be mentioned that the annealing process takes up to 24 hours to obtain maximum hard magnetic properties. Growth of the cell structure occurs primarily during the isothermal aging procedure and involves the diffusion of samarium.

In magnets with high coercivities $(>800 \mathrm{kA} / \mathrm{m})$ thin platelets (C) are found perpendicular to the hexagonal $c$-axis Fig. 1(b). High resolution electron microscope investigations show that the crystal structure of the platelet phase is close to the hexagonal $\mathrm{Sm}_{2} \mathrm{Co}_{17}$ structure Fig. 2(a). Contrary to high coercivity magnets which contain large crystallographic twins, a microtwinning within the cell interior phase (A) is observed by 


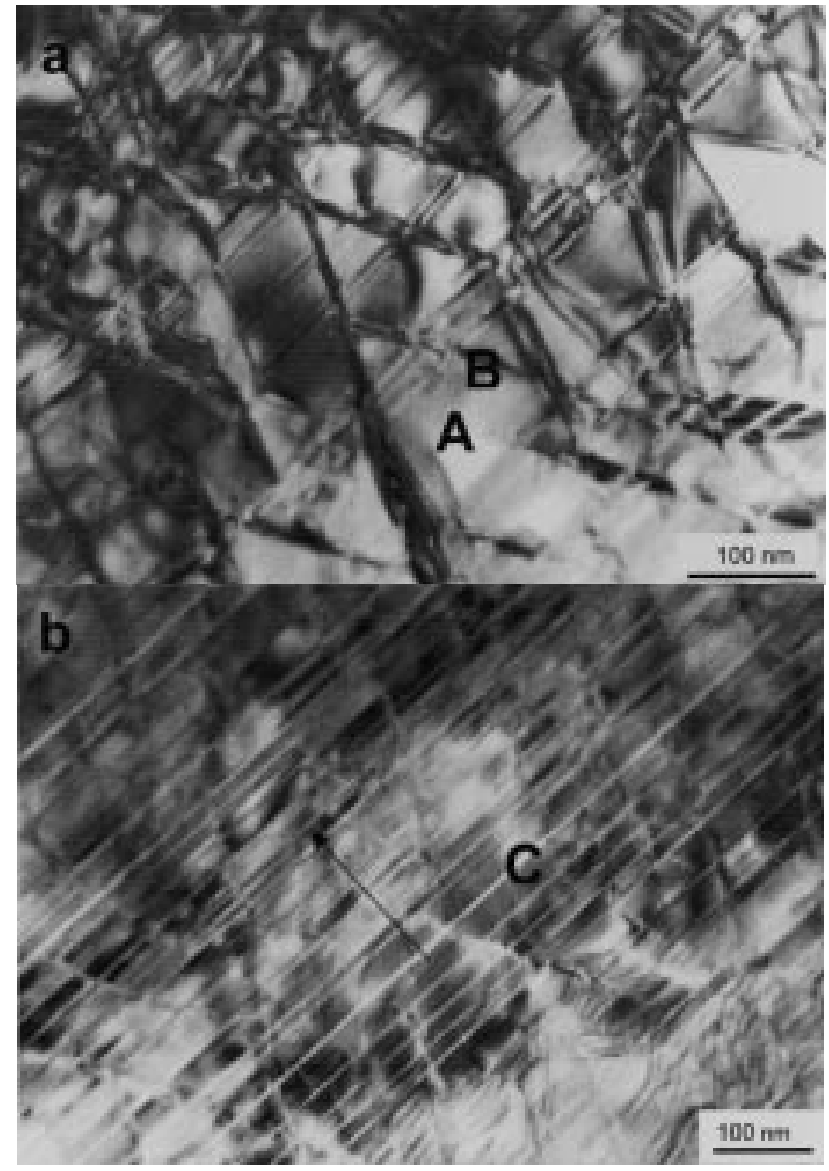

Fig. 1. Transmission electron images showing rhombic cells of $\mathrm{Sm}_{2}(\mathrm{Co}, \mathrm{Fe})_{17}$ (A) which are separated by a $\mathrm{Sm}(\mathrm{Co}, \mathrm{Cu}, \mathrm{Zr})_{5-7}$-cell boundary phase (B). A high density of the platelet phase (C) is found perpendicular to alignment direction marked by an arrow.

high resolution electron microscopy in low coercivity magnets $(<500 \mathrm{kA} / \mathrm{m})$ Fig. 2(b). The Lorentz electron microscope Foucault image of Fig. 3 shows that the cellular precipitation structure acts as attractive pinning center for magnetic domain walls in the remanent state and determines the magnetization reversal process. Maximum coercivities $(2000 \mathrm{kA} / \mathrm{m})$ were found in magnets with cell diameters of about $200 \mathrm{~nm}$. The compositional difference between the cell boundary phase (B) and the cell interior phase (A) determines the coercive field. The platelet phase (C) predominately acts as diffusion path for the transition metals and leads to a better chemical redistribution after the isothermal aging treatment and therefore to a higher coercivity of the magnet. Impurities, primarily such as oxygen and carbon, lead to the formation of macroscopic precipitates of the SmiOs, $\mathrm{ZrC}$, TiC etc. and therefore impede the formation of the platelet phase (C) and finally impede the chemical redistribution process.

\section{Micromagnetic Simulation}

\section{A. Micromagnetic and Numerical Background}

Micromagnetism starts from the total magnetic Gibb's free energy, $E$, of a ferromagnetic system, which is the sum of the

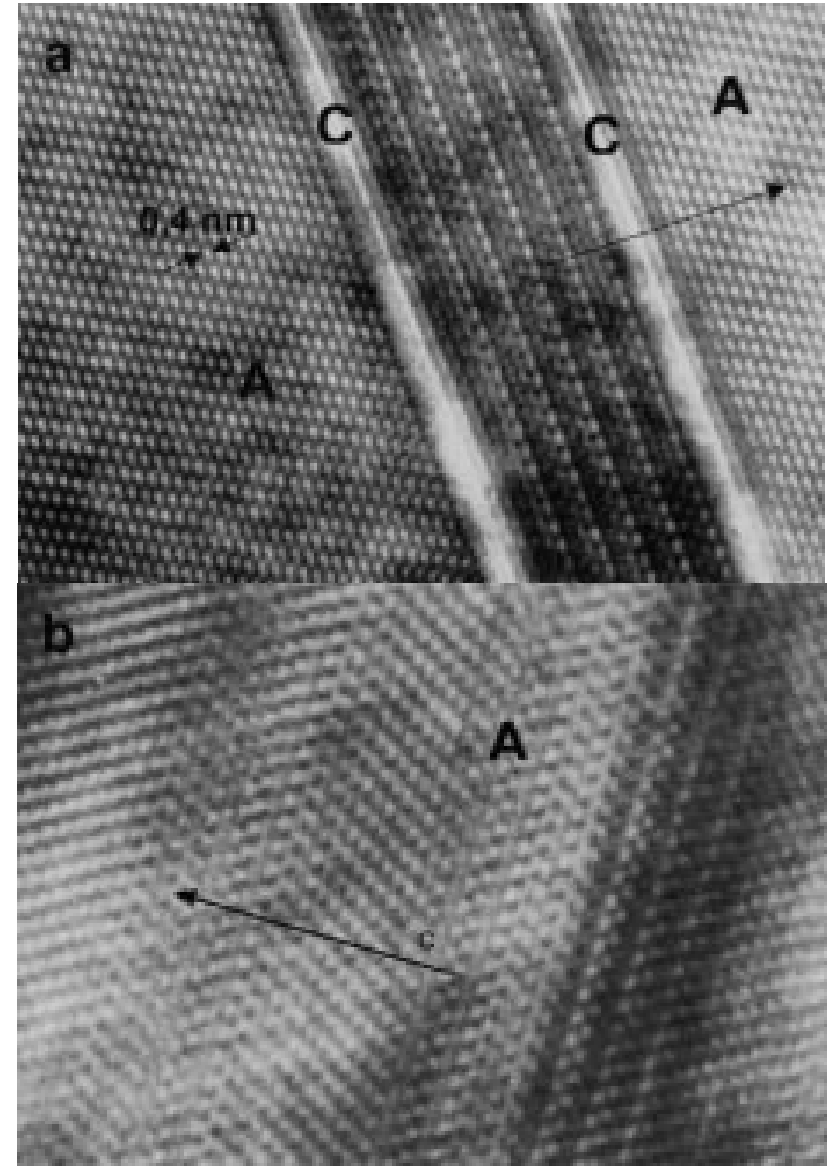

Fig. 2. High resolution electron micrographs showing cell matrix (A) and platelet phase (C) in a high coercivity magnet (a). Low coercivity is found in magnets with microtwins instead of platelets.

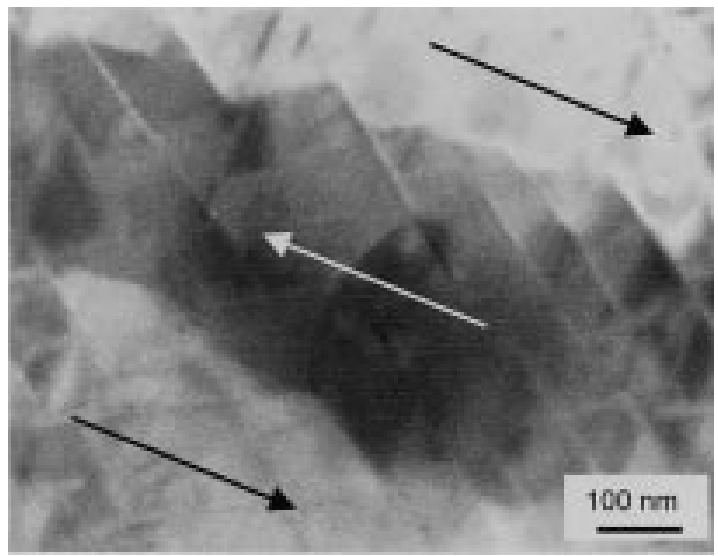

Fig. 3. Foucault electron micrograph showing the attractive pinning of domain walls in the remanent state at the continuous $\operatorname{Sm}(\mathrm{Co}, \mathrm{Cu})_{5-7}$ cell boundary phase. The arrows indicate the magnetization directions inside the domains.

exchange energy, the magneto-crystalline anisotropy energy, the magnetostatic energy, and the Zeeman energy [12]

$$
\begin{gathered}
E_{t}=\int\left[A \sum_{i=1}^{3}\left(\nabla \beta_{i}\right)^{2}-K_{1}(\boldsymbol{J} \cdot \boldsymbol{u})^{2}-\frac{1}{2} \boldsymbol{J} \cdot \boldsymbol{H}_{d}\right. \\
\left.-\boldsymbol{J} \cdot \boldsymbol{H}_{\mathrm{ext}}\right] d V
\end{gathered}
$$




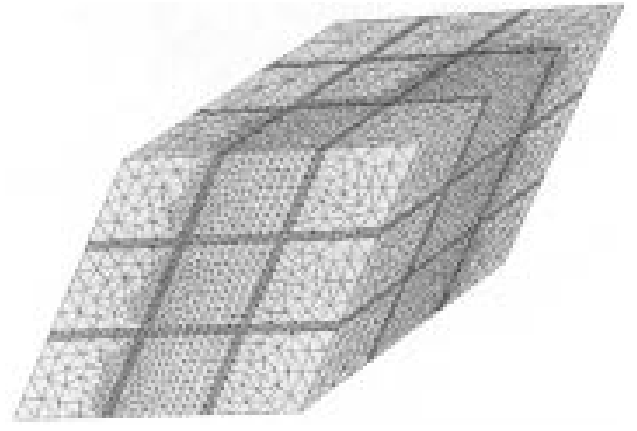

Fig. 4. Finite element model of the cellular structure of a the $\operatorname{Sm}(\mathrm{Co}, \mathrm{Fe}, \mathrm{Cu}$, $\mathrm{Zr})_{6-8}$ magnet. The bright and dark regions denote the rhombohedral cells and the cell boundary phase, respectively.

TABLE I

UNITS FOR MAGNETIC PROPERTIES

\begin{tabular}{lcllll}
\hline Phase & $\mathrm{T}$ & $J_{\mathrm{s}}(\mathrm{T})$ & $K_{1}\left(\mathrm{MJ} / \mathrm{m}^{3}\right)$ & $A(\mathrm{pJ} / \mathrm{m})$ & $\delta_{0}(\mathrm{~nm})$ \\
\hline $\mathrm{Sm} \mathrm{m}_{2}(\mathrm{Co}, \mathrm{Fe})_{17} /$ matrix & $300 \mathrm{~K}$ & 1.3 & 5 & 14 & 1.67 \\
$\mathrm{Sm}(\mathrm{Co}, \mathrm{Cu}, \mathrm{Zr})_{5-7} /$ boundary & $300 \mathrm{~K}$ & 0.8 & 1.9 & 14 & 2.71 \\
\hline $\mathrm{Sm}_{2}(\mathrm{Co}, \mathrm{Fe})_{17} /$ matrix & $400 \mathrm{~K}$ & 1.23 & 3.3 & 12.6 & 1.95 \\
$\mathrm{Sm}(\mathrm{Co}, \mathrm{Cu}, \mathrm{Zr})_{5-7} /$ boundary & $400 \mathrm{~K}$ & 0.76 & 1.1 & 12.6 & 3.38 \\
\hline $\mathrm{Sm} \mathrm{m}_{2}(\mathrm{Co}, \mathrm{Fe})_{17} /$ matrix & - & 1.3 & 5 & 14 & 1.67 \\
$\mathrm{Sm}\left(\mathrm{Co}_{0}, \mathrm{Cu}, \mathrm{Zr}\right)_{5-7} /$ boundary & - & 0.8 & 7.76 & 14 & 1.34 \\
\hline
\end{tabular}

Here $A$ denotes the ferromagnetic exchange constant, $J$ is the magnetic polarization $J=J_{s}\left(\beta_{1}, \beta_{2}, \beta_{3}\right)=\mu_{0} M$, and $\boldsymbol{M}$ is the magnetization. $\boldsymbol{H}_{\text {ext }}$ and $\boldsymbol{H}_{d}$ denote the external field and the demagnetizing field, respectively. $K_{1}$ is anisotropy constant, and $\boldsymbol{u}$ denotes the unit vector parallel to the $c$-axis. When the direction cosines of the magnetization $\beta_{i}$ are approximated by piecewise linear functions on the finite element mesh, the energy functional (1) reduces to an energy function with the nodal values of the direction cosines as unknowns. Its minimization with respect to the direction cosines of the magnetization at the nodal points, subject to the constraint $|\boldsymbol{J}|=J_{s}$, provides an equilibrium distribution of the magnetization. To satisfy the constraint, the magnetization can be represented by polar coordinates. The resulting algebraic minimization problem is solved using a quasi-Newton conjugate gradient technique [13]. Conjugate gradient based method requires the energy and the gradient of the energy to search for local minima. We follow a procedure described by Newell and co-workers [14] to evaluate the gradients in polar coordinates. The demagnetizing field $\boldsymbol{H}_{\boldsymbol{d}}$ follows from the magnetic scalar potential which is calculated using a hybrid finite element/boundary technique [15].

\section{B. Finite Element Model and Intrinsic Properties}

Fig. 4 presents the finite element model of the cellular microstructure, consisting of 27 cells. The model takes into account the cell interior phase (A) and the cell boundary phase (B) but neglects the platelet phase (C). The cells are divided into tetrahedral finite elements. The total number of finite elements ranges from about 100.000-200.000, depending on the cell size. In order to account for the magnetization transition near the domain walls, we use a so-called geometrical mesh [16]. The mesh is gradually refined toward the cell boundary phase, reaching a mesh size comparable to the domain wall width near the cell boundaries.

Table I summarizes the intrinsic magnetic properties used for the calculations. The first two sets of parameter were

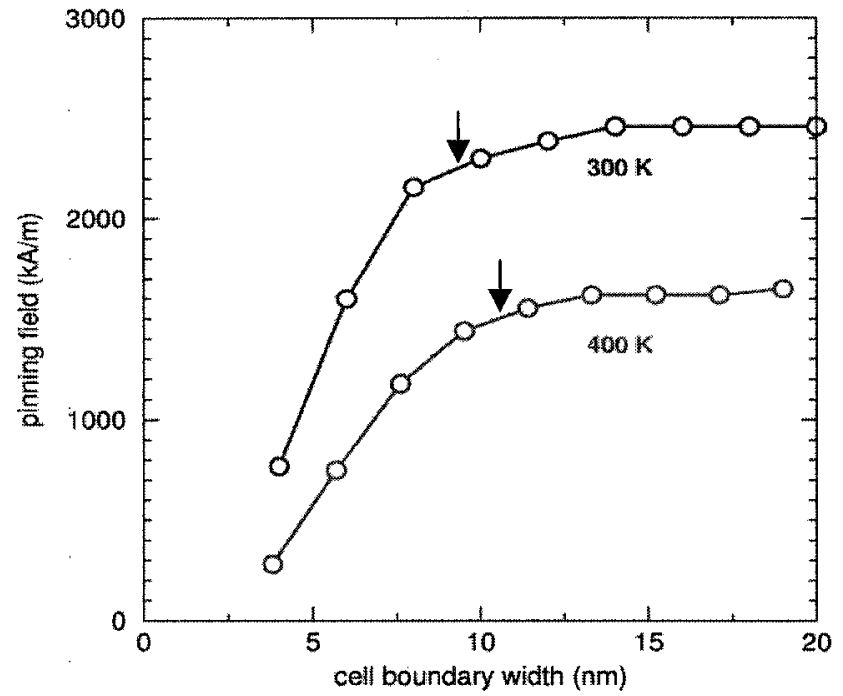

Fig. 5. Calculated pinning field as a function of the cell size for $300 \mathrm{~K}$ and $400 \mathrm{~K}$. The arrows indicate the domain wall width $\pi \delta_{0}$ of the cell boundary phase.

taken from [17]. The magneto-crystalline anisotropy of the cell boundary phase is reduced as compared the anisotropy of the matrix phase. As a consequence the wall energy is lower within the cell boundary which gives rise to attractive domain wall pinning. Durst and co-workers [17] derived the intrinsic magnetic properties of the cell matrix $\mathrm{Sm}_{2}(\mathrm{Co}, \mathrm{Fe})_{17}$ and the cell boundary $\mathrm{Sm}(\mathrm{Co}, \mathrm{Cu}, \mathrm{Zr})_{5-7}$ from the analysis of magnetization curves parallel and perpendicular to the alignment direction. The anisotropy constant of the cell matrix is about 2.6 times larger than the anisotropy constant of the cell boundary phase. The exchange constant was assumed to be the same for both phases, because of similar values of the Curie temperature. The exchange constant was derived from the effective wall energy which was obtained from closure domains of a $\mathrm{Sm}(\mathrm{Co}, \mathrm{Fe}, \mathrm{Cu}, \mathrm{Zr})_{7.6}$ magnet. The third set of parameters are used to model repulsive pinning. Here the $K_{1}$ value of the cell boundary phase is higher than that of the matrix phase. In addition, Table I lists the Bloch parameter $\delta_{0}=\left(A / K_{1}\right)^{1 / 2}$, which gives the minimum extension of magnetic inhomogenities.

\section{Numerical Results}

The pinning field was calculated as a function of the cell boundary width for different intrinsic magnetic properties. The initial state for the calculations is a two-domain state. The subsequent minimization of (1) for increasing external field simulates the motion of the domain wall toward the cell boundary phase. The external field is applied parallel to the $c$-axis. With increasing field, the domain with the magnetization parallel to the field direction grows. The domain will become pinned at the grain boundary phase.

Fig. 5 gives the pinning field as function of the cell boundary width for the first two parameters sets in Table I. Keeping the composition of the magnet constant, the width of the cell boundary increases linearly with increasing cell size. The decrease of the maximum pinning field with increasing temperature has to be attributed to the decrease of 

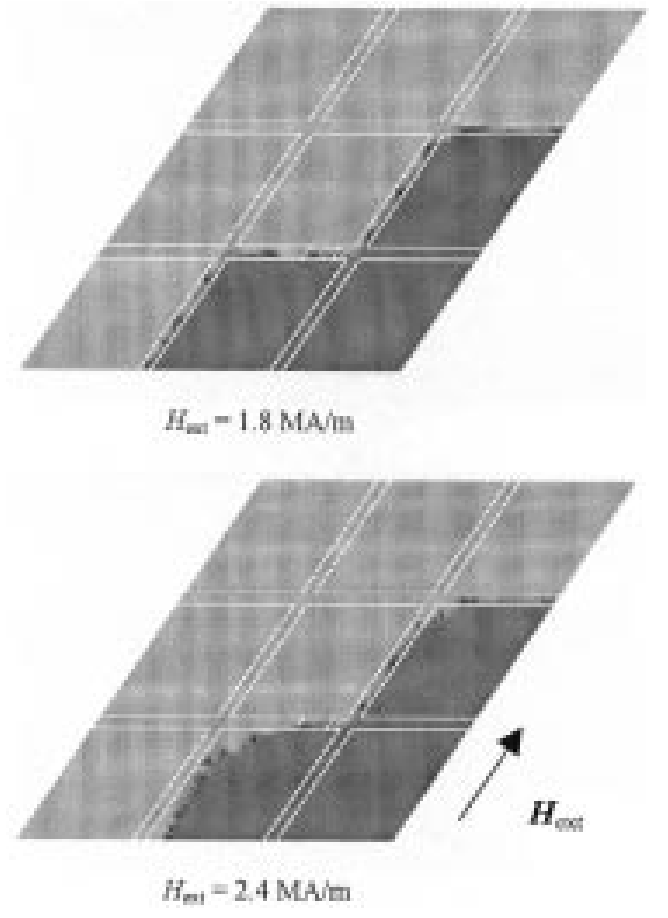

Fig. 6. Calculated domain images at different applied fields for a cell size of $160 \mathrm{~nm}$, a cell boundary width is $6 \mathrm{~nm}$, and $T=300 \mathrm{~K}$. The grey scale plot denotes magnetization components parallel to the $c$-axis.

$\Delta K_{1}=K_{1}^{\text {matrix }}-K_{1}^{\text {boundary }}$ from $\Delta K_{1}=3.1 \mathrm{MJ} / \mathrm{m}^{3}$ to $\Delta K_{1}=2.2 \mathrm{MJ} / \mathrm{m}^{3}$. In order to obtain the maximum pinning fields $(2.4 \mathrm{MA} / \mathrm{m}$ at $300 \mathrm{~K}$ and $1.6 \mathrm{MA} / \mathrm{m}$ at $400 \mathrm{~K})$, the cell boundary width must exceed the domain wall width, $\pi \delta_{0}$, of the cell boundary phase. The pinning field at $300 \mathrm{~K}$ reaches only 1-2 MA/m for a cell boundaries thickness of $3 \mathrm{~nm}$ and $6 \mathrm{~nm}$, respectively. The domain wall forms a complex structure near the cell boundary phase. Thus the calculated pining field depends on the $3 \mathrm{D}$ domain wall configuration which is not stray field free, in addition to the wall energy difference between the two phases. Fig. 6 gives the calculated domain patterns for $300 \mathrm{~K}$ in a slice plane parallel to the $c$-axis for different applied fields. As the external field is increased the wall breaks away from cell boundary phase. Depinning of the domain wall starts at the corners of the cell boundary. The domain patterns of Fig. 6 are only a two-dimensional representation of a three-dimensional magnetization structure and are in agreement with the image of Fig. 3 obtained from Lorentz electron microscopy. According to the complex cellular precipitation structure, the domain wall is heavily bent. The depinning causes a further bowing of the domain wall. This process is illustrated in Fig. 7, which shows the trace of the domain wall within the cellular microstructure at different applied field.

Finally, the pinning field owing to repulsive pinning was calculated, using the parameter set 3 of Table I. The pinning field was in the range from $2.1-2.6 \mathrm{MA} / \mathrm{m}$ for a thickness of the cell boundary phase of $6 \mathrm{~nm}$ and $10 \mathrm{~nm}$, respectively. The trace of the domain wall, depicted in Fig. 8 clearly, shows that the wall is pushed toward the cell boundary phase. As the wall energy is higher within the cell boundary phase, the center of the wall remains in the matrix phase.
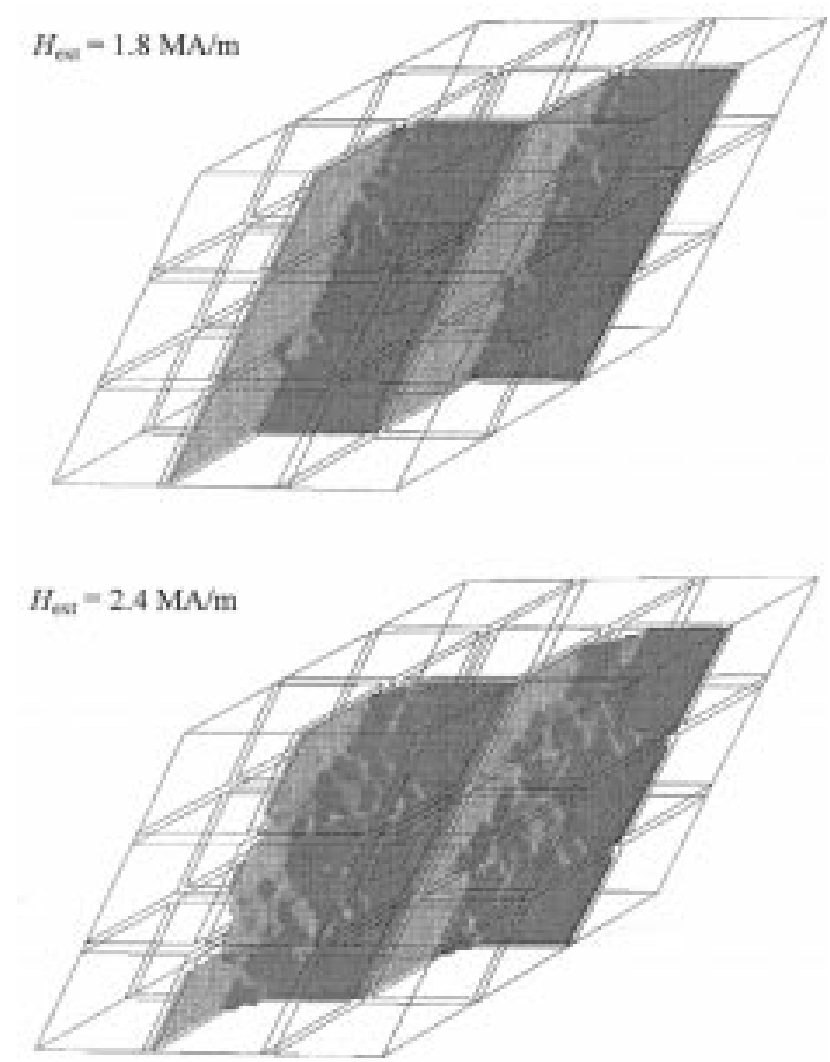

Fig. 7. Interaction of a domain wall with the cellular structure. The 3D images give the trace of the domain wall.

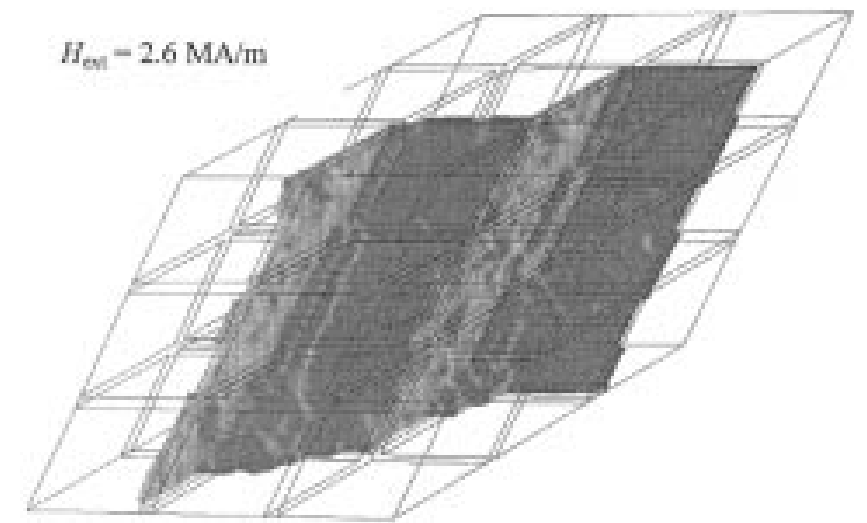

Fig. 8. Trace of the domain wall at $H_{\mathrm{cxt}}=2.6 \mathrm{MA} / \mathrm{m}$ in the case of repulsive pinning.

\section{SUMMARY}

A 3D finite element method was used to simulate domain wall pinning in $\mathrm{SmCo}_{5} / \mathrm{Sm}_{2} \mathrm{Co}_{17}$ based permanent magnets. The finite element model was built according to the cellular microstructure obtained from TEM investigations (Fig. 1). The numerical results show a strong influence of the dimension of the cell boundary phase on the coercive field, which significantly increases with the extension of the $1: 5 / 7$-type cell boundary phase:

- Exact precipitation structure parameters (controlled by composition and processing) and the exact values of 
$J_{s}(T), K_{1}(T)$ and $A(T)$ are necessary to explain the coercive field at high temperature.

- In order to obtain sufficient high coercivity at high temperatures $\left(>400^{\circ} \mathrm{C}\right)$ the $\mathrm{Cu}$-concentration has to be increased. The resulting increase of the difference between the $K_{1}$-values of cell boundary and matrix phases explain the increase of coercivity at high temperatures.

- A minimum width of the cell boundary phase is necessary to obtain high pinning fields. With decreasing $K_{1}$ of the cell boundary phase, the thickness $D$ of the cell boundary phase has to be increased in order to meet the condition $D>\pi \delta_{0}$.

\section{REFERENCES}

[1] K. J. Strnat, "Rare earth-cobalt permanent magnets," in Ferromagnetic Materials, E. P. Wohlfarth and K. H. J. Buschow, Eds. Amsterdam: Elsevier Science, 1988, vol. 4, pp. 131-209.

[2] J. D. Livingston and D. L. Martin, "Microstructure of aged $(\mathrm{Co}, \mathrm{Cu}$, $\mathrm{Fe})_{7} \mathrm{Sm}$ magnets," J. Appl. Phys., vol. 48, pp. 1350-1354.

[3] J. Fidler, "Coercivity of precipitation hardened cobalt rare earth 17:2 permanent magnets," J. Magn. Magn. Mat., vol. 30, pp. 58-70, 1982.

[4] M. Katter, "Coercivity calculation of $\mathrm{Sm}_{2}(\mathrm{Co}, \mathrm{Fe}, \mathrm{Cu}, \mathrm{Zr})_{17}$ magnets," $J$. Appl. Phys., vol. 83, pp. 6721-6723, 1998.

[5] S. T. Chui, "Pinning of domain walls in $\mathrm{Sm}(\mathrm{Co}, \mathrm{Fe}, \mathrm{Cu}, \mathrm{Zr})_{z}$ at finite temperatures," J. Magn. Magn. Mater., vol. 202, pp. 133-140, 1999.
[6] S. Liu, J. Yang, G. Doyle, G. E. Kuhl, C. Chen, M. Walmer, M. Walmer, and G. Simon, "New sintered high temperature Sm-Co based permanent magnet materials," IEEE Trans. Magn., vol. 35, pp. 3325-3327, 1999.

[7] W. Tang, Y. Zhang, and G. C. Hadjipanayis, "Effect of Zr on the microstructure and magnetic properties of $\mathrm{Sm}\left(\mathrm{Co}_{b a l} \mathrm{Fe}_{0.1} \mathrm{Cu}_{0.088} \mathrm{Zr}_{x}\right)_{8.5}$ magnets," J. Appl. Phys., vol. 87, pp. 399-403, 2000.

[8] J. Fidler, P. Skalicky, and F. Rothwarf, "High resolution electron microscope study of $\mathrm{Sm}(\mathrm{Co}, \mathrm{Fe}, \mathrm{Cu}, \mathrm{Zr})_{7.5}$ magnets," IEEE Trans. Magn., vol. 19, pp. 2041-2043, 1983.

[9] R. K. Mishra, G. Thomas, T. Yoneyama, A. Fukuno, and T. Ojima, "Microstructure and properties of step aged rare earth alloy magnets," $J$. Appl. Phys., vol. 52, pp. 2517-2519, 1981.

[10] L. Rabenberg, R. K. Mishra, and G. Thomas, "Microstructures of precipitation-hardened SmCo permanent magnets," J. Appl. Phys., vol. 53, pp. 2389-2391, 1982.

[11] A. E. Ray, "Metallurgical behavior of $\mathrm{Sm}(\mathrm{Co}, \mathrm{Fe}, \mathrm{Cu}, \mathrm{Zr})_{z}$ alloys," $J$. Appl. Phys., vol. 55, pp. 2094-2096, 1984.

[12] W. F. Brown Jr., Micromagnetics. New York: Wiley, 1963.

[13] P. E. Gill, W. Murray, and M. H. Wright, Practical Optimization. London: Academic, 1993.

[14] A. J. Newell and R. T. Merrill, "The curling nucleation mode in a ferromagnetic cube," J. Appl. Phys., vol. 84, pp. 4394-4402, 1998.

[15] D. R. Fredkin and T. R. Koehler, "Hybrid method for computing demagnetizing fields," IEEE Trans. Magn., vol. 26, pp. 415-417, 1990

[16] B. Szabo and I. Babuska, Finite Element Analysis. New York: Wiley, 1991.

[17] K.-D. Durst, H. Kronmüller, and W. Ervens, "Investigations of the magnetic properties and demagnetization processes of an extremely high coercive $\mathrm{Sm}(\mathrm{Co}, \mathrm{Cu}, \mathrm{Fe}, \mathrm{Zr})_{7.6}$ permanent magnet-I. Determination of intrinsic magnetic properties," Phys. Stat. Sol. (a), vol. 108, pp. 403-416, 1988. 